\title{
Kinetics and Products from Heterogeneous Oxidation of Squalene with Ozone
}

\author{
Shouming Zhou, Matthew W. Forbes, Jonathan P.D. Abbatt
}

\begin{abstract}
Version Post-print/Accepted Manuscript
Citation Zhou, S., Forbes, M.W., Abbatt, J.P.D., 2016. Kinetics and Products (published version) from Heterogeneous Oxidation of Squalene with Ozone. Environ. Sci. Technol. 50, 11688-11697. https://doi.org/10.1021/acs.est.6b03270.

Copyright / License This document is the Accepted Manuscript version of a Published Work that appeared in final form in Environmental Science \& Technology, copyright (C) American Chemical Society after peer review and technical editing by the publisher. To access the final edited and published work see https://pubs.acs.org/doi/10.1021/acs.est.6b03270.
\end{abstract}

How to cite TSpace items

Always cite the published version, so the author(s) will receive recognition through services that track citation counts, e.g. Scopus. If you need to cite the page number of the author manuscript from TSpace because you cannot access the published version, then cite the TSpace version in addition to the published version using the permanent URI (handle) found on the record page.

This article was made openly accessible by $U$ of $T$ Faculty. Please tell us how this access benefits you. Your story matters. 


\title{
Kinetics and Products from Heterogeneous Oxidation of Squalene with Ozone
}

\author{
Shouming Zhou*, Matthew W. Forbes, Jonathan P.D. Abbatt
}

Department of Chemistry, University of Toronto

80 St. George St.

Toronto, ON, Canada M5S 3H6

\begin{abstract}
Motivated by the importance of the heterogeneous chemistry of squalene contained within skin oil to indoor air chemistry, the surface reaction of squalene with gas-phase ozone has been investigated. Using direct analysis in real time-mass spectrometry (DART-MS) to monitor squalene, the reactive uptake coefficient was determined to be $(4.3 \pm 2.2) \times 10^{-4}$ and $(4.0 \pm 2.2) \times 10^{-4}$ for ozone mixing ratios (MRO3) of 50 and $25 \mathrm{ppb}$, respectively, on squalene films deposited on glass surfaces. At MRo3 $=25 \mathrm{ppb}$, the lifetime for oxidation was the same as that in an indoor office with $\mathrm{MRO}_{03}$ between 22 and $32 \mathrm{ppb}$, suggesting that $\mathrm{O}_{3}$ was the dominant oxidant in this indoor setting. While the heterogeneous kinetics of squalene $/ \mathrm{O}_{3}$ were independent of relative humidity $(\mathrm{RH})$, the $\mathrm{RH}$ significantly affected the reaction products. Under dry condition $(\mathrm{RH}<5 \%)$, in addition to several products between $\mathrm{m} / \mathrm{z}$ 300-350 the major condensed-phase end products were levulinic acid (LLA) and succinic acid (SCA). Under humid conditions ( $\mathrm{RH}=50 \%$ ), the major end products were 4-oxopentanal, 4-oxobutanoic acid and levulinic acid (LLA). The molar yields of LLA and SCA were quantified as $(230 \pm 43) \%$ and $(110 \pm 31) \%$, respectively, under dry condition, and $(91 \pm 15) \%$ and $<5 \%$, respectively, at 50\% RH. Moreover, high molecular weight (HMW, molecular weight $>$ $450 \mathrm{Da}$ ) products were observed under dry conditions with indications that levulinic acid was involved in their formation. The mechanism of squalene oxidation is discussed in light of these observations, with indications of an important role played by Criegee intermediates.
\end{abstract}

\section{INTRODUCTION}

It was recognized recently that chemistry between unsaturated constituents of skin oil lipids and gas-phase oxidants, e.g. ozone, plays an important role in indoor air chemistry. ${ }^{1}$ Extensive studies on the chemical composition of skin surface lipids reveal that squalene is one of the most common chemicals produced by skin cells, accounting for $\sim 10 \%$ by mass of skin lipid material..$^{2-7}$ The chemistry of squalene in indoor environments is, however, not fully established.

With six carbon-carbon double bonds $(\mathrm{C}=\mathrm{C})$ present in the molecule, squalene is a highly unsaturated 
triterpene (Figure 1). Therefore it is reactive toward atmospheric oxidants, such as ozone. From previous studies focusing on the squalene $/ \mathrm{O}_{3}$ reaction, ${ }^{8-15}$ the gas-phase products from ozonolysis of squalene have been well characterized. For example, by measuring products from ozone reaction with aircraft cabin materials, ${ }^{14,16,17}$ soiled clothes, ${ }^{9}$ human hair ${ }^{18}$ and skin, ${ }^{15}$ it is known that a series of carbonyls, such as acetone, 6-methyl-5-hepten-2-one (6-MHO) and 2,6-dimethyl-2,6-undecadien-10-one (geranyl acetone) are formed as primary products from the reaction, ${ }^{15,19,20}$ and dicarbonyls, such as 4-oxopentanal (4-OPA), 1,4-butanedial (succinic dialdehyde), 4-methyl-8-oxo-4-nonenal (4-MON) and 4-methyl-4-octene-1,8dial (4-MOD) are produced as secondary or higher order reaction products (Figure S1). ${ }^{15}$ Among them, 6-MHO and 4-OPA have also been detected in forest air resulting from squalene oxidation. ${ }^{21,22}$ In addition, secondary organic aerosol has been reported from the squalene/ $\mathrm{O}_{3}$ reaction. ${ }^{23}$

By contrast, investigations of the condensed-phase products from ozone reaction with squalene are limited. Most recently, using a direct analysis in real time-mass spectrometry (DART-MS) technique, we studied the chemical changes occurring in the condensed-phase when skin oil was exposed to ozone, yielding evidence for the formation of highly oxygenated products, largely composed of carboxylic acids. ${ }^{24}$ Interestingly, two major products, succinic acid and levulinic acid, were observed as major projects from both skin oil oxidation and preliminary studies of pure squalene oxidation. This is in accord with earlier work showing that the condensed-phase products from ozonolysis of squalene were more hydrophilic than the precursor. ${ }^{25} \mathrm{~A}$ recent study reported the formation of high molecular weight products up to $1450 \mathrm{Da}$ when squalene was exposed to extremely high mixing ratios of ozone $\left(\mathrm{MRO}_{3}=50 \mathrm{ppm}\right){ }^{26}$

There have been three prior studies of the heterogeneous kinetics of ozone reaction with squalene but the reported reactive uptake coefficients $(\gamma)$ disagree. Wells et al. first measured $\gamma$ of $(4.5 \pm 1.4) \times 10^{-4}$ for 50 ppb ozone on squalene film on glass. ${ }^{20}$ This value is in reasonably good agreement with the kinetics measured by Fu et al., ${ }^{25}$ who used attenuated total reflection infrared spectroscopy (ATR-IR) and reported $\gamma$ of $(5.1 \pm 0.7) \times 10^{-4}$ from the increase in $\mathrm{C}=\mathrm{O}$ band absorption in the oxidation products, which are higher than $\gamma$ of $(1.7 \pm 0.2) \times 10^{-4}$ from the decrease of $\mathrm{C}=\mathrm{C}$ band absorption in squalene. Using the same techniques, Petrick and Dubowski ${ }^{27}$ reported that the kinetics with $40 \mathrm{ppb}$ ozone were lower than other measurements by a factor of $\sim 45$. The reason for this large discrepancy is not fully known, but Petrick and Dubowski ${ }^{27}$ pointed out that the kinetics measured by Wells et al. were determined by monitoring gas-phase ozone concentrations, which might be affected by secondary reactions between ozone and intermediate products. The ATR-IR technique used in other studies to monitor the $\mathrm{C}=\mathrm{C}$ or $\mathrm{C}=\mathrm{O}$ band absorption may also experience interference from the intermediate products that contain $\mathrm{C}=\mathrm{C}$ and/or $\mathrm{C}=\mathrm{O}$ bonds.

In this work we investigate the heterogeneous reaction of squalene with gas-phase ozone using DARTMS. DART is an ambient soft ionization technique that is able to produce the intact protonated and/or ammoniated molecules with little or no fragmentation. ${ }^{28}$ The main objectives of this work are: (i) to determine the kinetics and condensed-phase products for squalene $/ \mathrm{O}_{3}$ reaction system under ozone mixing ratios that are environmentally relevant; (ii) to investigate the effect of ambient conditions, such as relative humidity ( $\mathrm{RH}$ ), on the reaction; and (iii) to measure the oxidation kinetics of squalene under genuine indoor conditions in order to assess the contribution of the $\mathrm{O}_{3}$ reaction to squalene oxidation in indoor 
settings. This work builds upon our earlier studies of skin oil oxidation, ${ }^{24}$ wherein preliminary investigation of pure squalene oxidation was reported. Now we provide more detailed work on the suite of reaction products, the reactive uptake coefficient, and the RH dependence to this chemistry. As well, the kinetics of ozone-driven loss of pure squalene informs us on the rate at which squalene will react with ozone when mixed in skin lipid material.

\section{EXPERIMENTAL SECTION}

Chemicals and Reagents. Squalene (liquid, $\geq 98 \%$ ) was purchased from Sigma-Aldrich (Canada). Acetonitrile (ACN), dichloromethane (DCM), methanol, levulinic acid and succinic acid were purchased from VWR (Canada). All the chemicals and reagents were used as received.

Squalene Film Generation. The squalene film was generated in a manner analogous to our previous work on benzo[e]pyrene ${ }^{29} 100$ and $40 \mu \mathrm{g} / \mathrm{mL}$ squalene solutions in ACN and DCM $(1: 1=\mathrm{v} / \mathrm{v})$ were prepared for kinetics and product studies, respectively. Home-made Teflon capillary holders were used to hold 10 glass melting point capillaries with their bottom ends sealed. Using a microsyringe ( $10 \mu \mathrm{L}, \mathrm{SGE}$ Analytical Science, Australia) $1 \mu \mathrm{L}$ squalene solution was deposited outside the sealed end of the capillary. After the solvents evaporate, a thin film with 100 and 40 ng squalene for kinetic and product studies, respectively, is formed. For a film geometric area of $\sim 4 \mathrm{~mm}^{2}$ on the capillary the squalene surface coverage is estimated to be $<3.7 \times 10^{15}$ molecules $/ \mathrm{cm}^{2}$, indicating that the films are extremely thin, close to a monolayer coverage (which would be approximiately $10^{15}$ molecules $/ \mathrm{cm}^{2}$ ).

Squalene Oxidation with $\mathbf{O}_{3}$ and Indoor Air. The oxidation of squalene by ozone was carried out at $(295 \pm 3) \mathrm{K}$ by placing the capillary holder in a flow tube where a flow of air $(1.8 \mathrm{slm})$ mixed with ozone was introduced. The flow tube was a cylindrical glass tube $(\sim 6.0 \mathrm{~cm}$ i.d. and $\sim 60 \mathrm{~cm}$ long $)$ with an inlet and outlet flange mounted on both ends. Ozone was generated by passing $900 \mathrm{sccm}$ air through an ozone generator that is composed of a quartz cell and a Pen-Ray lamp. A moveable metal cover outside the lamp was used to regulate the ozone generation rate, and thus the ozone mixing ratios in the flow tube. The ozone flow was then mixed with another $900 \mathrm{sccm}$ dry or humidified air prior to introduction into the flow tube. Humidified air was generated by passing $900 \mathrm{sccm}$ air through a bubbler that was filled with distilled water $(18 \mathrm{M} \Omega \cdot \mathrm{cm})$. The ozone residence time in the flow tube was $\sim 40 \mathrm{~s}$. The MRo3 and RH were monitored by a UV photometric $\mathrm{O}_{3}$ analyzer (Thermo Model 49i) and a hygrometer (Vaisala, U.S.A.), respectively, from the outlet flow.

Squalene oxidation in indoor air was performed by placing the capillaries on which $100 \mathrm{ng}$ squalene was deposited in an office in the Chemistry Department, University of Toronto, where the temperature, RH, and ozone mixing ratio were monitored (Figure S2). The light spectrum in the office was also measured by a spectral radiometer (StellarNet Inc., U.S.A.). The oxidized samples from the flow tube or the office setting were stored in a desiccator where a flow of nitrogen was added to avoid contamination from the room air before analysis. 
DART-MS Analysis of Squalene and Oxidation Products. Squalene and its oxidation products were analyzed with DART-MS, using a method described in detail in our previous work. ${ }^{24}$ The capillary holder was placed on a motorized rail at a speed of $0.3 \mathrm{~mm} / \mathrm{s}$ between the ion source and MS inlet. A flow of helium $(\sim 3.0 \mathrm{slm})$ was used in the DART source that was held at $\sim 500{ }^{\circ} \mathrm{C}$. A Vapur Interface (IonSense Inc., Saugus, MA) with a ceramic inlet was mounted between the linear rail and the MS inlet. A diaphragm pump was used to adjust a total flow of $\sim 3.8 \mathrm{slm}$ through the ceramic tube. The DART-MS was operated under both positive and negative modes to monitor squalene and its oxidation products. Under positive ion mode, most spectra represent prononated $\left(\left[\mathrm{M}+\mathrm{H}^{+}\right]^{+}\right)$or sometimes ammoniated $\left(\left[\mathrm{M}+\mathrm{NH}_{4}{ }^{+}\right]^{+}\right)$species, whereas in negative ion mode there is commonly loss of a proton to form $\left(\left[\mathrm{M}-\mathrm{H}^{+}\right]\right)^{-}$ions. The MS was a JMS-T100LC time-of-flight mass spectrometer (JEOL USA Inc., Peabody, MA) with a mass resolution of $\sim 6000$ at $\mathrm{m} / \mathrm{z} 600$.

Product Quantification. In order to determine the product yields from squalene $/ \mathrm{O}_{3}$ reaction, squalene and two oxidation products, levulinic acid (LLA) and succinic acid (SCA), were calibrated with positive and negative ion DART-MS, respectively. The calibrations were made by depositing $1 \mu \mathrm{L}$ squalene in $\mathrm{DCM} / \mathrm{ACN}$ or the acids in methanol resulting in 0-100 ng analyte on the capillaries and then analyzed with DART-MS. As mentioned in our previous work and as shown in Figure S3, squalene showed two peaks at $\mathrm{m} / \mathrm{z} 411.4$ and 428.4 under the positive mode DART-MS, corresponding to protonated $\left(\left[\mathrm{M}+\mathrm{H}^{+}\right]^{+}\right)$ and ammoniated $\left(\left[\mathrm{M}+\mathrm{NH}_{4}{ }^{+}\right]^{+}\right)$squalene, respectively. ${ }^{24}$ It was thus quantified by summing these two signals. Whereas, LLA and SCA produced deprotonated molecular ions ([M-H $\left.\left.{ }^{+}\right]^{-}\right)$at $\mathrm{m} / \mathrm{z} 115.0$ and 117.0, respectively, under negative ion DART-MS. The calibration curves for these three chemicals are given in Figure S4. The uncertainty in each data point reported represents one standard deviation $(1-\sigma)$ of the measurements from the 10 capillaries.

\section{RESULTS AND DISCUSSION}

Kinetics for the Heterogeneous Oxidation of Squalene with Ozone. Kinetic plots for the heterogeneous oxidation of squalene with ozone are given in Figure 2. The data for the control experiment ( $\left.\mathrm{MR}_{\mathrm{O} 3}=0 \mathrm{ppb}\right)$ demonstrate that the evaporative loss of squalene in the flow tube is negligible. The linear first-order decay curves in Figure 2 lead to the pseudo first-order rate coefficients $\left(\mathrm{k}_{1}\right.$ in $\left.\mathrm{s}^{-1}\right)$ of $(6.0 \pm 0.4) \times 10^{-4}$ and $(1.3 \pm 0.1) \times 10^{-3}$ for squalene oxidation with 25 and $50 \mathrm{ppb} \mathrm{O}_{3}$, respectively, where the uncertainties are (1$\sigma)$ precisions. Using the following equation (Eq. 1) the ozone uptake coefficient $(\gamma)$ on squalene film could be estimated: ${ }^{25}$

$k_{1}=-\gamma\left(\frac{P_{0}{ }_{3} v}{4 R T}\right)\left(\frac{S}{V}\right) /[\text { squalene }]_{0}$

where $\mathrm{k}_{1}$ is the pseudo first-order rate coefficient; $\mathrm{P}_{3}$ is ozone pressure and $v$ is the thermal speed of ozone in the gas-phase; $\mathrm{R}$ and $\mathrm{T}$ are the universal gas constant and temperature in the flow tube, respectively; $\mathrm{S} / \mathrm{V}$ is the surface area-to-volume ratio of the squalene film and [squalene] 0 is the initial squalene concentration on the capillary. An assumption of this kinetic analysis is that reactivity occurs within the 
squalene liquid film.

The thermal speed of gas-phase ozone is calculated by Eq. 2:

$v=\sqrt{8 R T / \pi M}$

where $\mathrm{M}$ is the molar mass of ozone.

By applying $\mathrm{k}_{1}=(1.3 \pm 0.1) \times 10^{-3} \mathrm{~s}^{-1}$ and $(6.0 \pm 0.4) \times 10^{-4} \mathrm{~s}^{-1}$ obtained for 50 and $25 \mathrm{ppb}$ ozone oxidation of squalene, respectively, the estimated surface area of the squalene film $\mathrm{S}=4 \pm 2 \mathrm{~mm}^{2}$ and $\mathrm{T}=295 \mathrm{~K}$, the respective $\gamma$ values are calculated to be $(4.3 \pm 2.2) \times 10^{-4}$ and $(4.0 \pm 2.2) \times 10^{-4}$. The uncertainty in this value is mainly due to the uncertainty in the estimation of the surface area of the squalene film. Nevertheless, the $\gamma$ obtained in this study for $50 \mathrm{ppb}$ ozone on a squalene film is in excellent agreement with that reported by Wells et al. $\left((4.5 \pm 1.4) \times 10^{-4}\right)^{20}$ and a bit lower than $\mathrm{Fu}$ et al.'s measurement from $\mathrm{C}=\mathrm{O}$ band absorption $\left((5.1 \pm 0.7) \times 10^{-4}\right) .{ }^{25}$ Even though it was claimed in the latter study that the lower $\gamma$ obtained from the $\mathrm{C}=\mathrm{C}$ band absorption $\left((1.7 \pm 0.2) \times 10^{-4}\right)$ is more accurate, as will be discussed later, our product study shows evidence for the formation of reactive intermediates that contain both $\mathrm{C}=\mathrm{C}$ and $\mathrm{C}=\mathrm{O}$ bonds, which may interfere with the ATR-IR measurements of squalene and its oxidation products, and possibly lead to a lower limit for the uptake coefficient measured from $\mathrm{C}=\mathrm{C}$ bond decay and an upper limit for that from $\mathrm{C}=\mathrm{O}$ bond formation in $\mathrm{Fu}$ et al.'s measurement.

As discussed in the Introduction, the $\gamma$ reported by Petrick and Dubowski ${ }^{27}$ is lower than other values by more than a factor of 10 . One of the reasons given by these authors is the multilayer deposition of squalene on the surface that could result in large amounts of squalene inaccessible to react with ozone, and hence lead to underestimation of the reaction kinetics. Given the linearity of the kinetic plots in Figure 2 and the high uptake coefficient obtained in this work, coupled with the thin nature of our films, this effect may not prevail in this study. With a thicker and more complex matrix however, the morphology and phases of the films and/or products may affect the kinetics significantly, as in our previous work where we observed that pure squalene reacts more rapidly than when present in skin oil. ${ }^{24}$

The $\gamma$ values for ozone uptake by unsaturated fatty acids, e.g. oleic acid and linoleic acid that contain 1 and $2 \mathrm{C}=\mathrm{C}$ respectively, are reported to be around $10^{-3} .{ }^{31}$ Both our studies and those in the literature $e^{20,25,27}$ suggest that the reaction of squalene with ozone is somewhat slower. It can be noted that studies on ${ }^{\circ} \mathrm{OH}$ radical uptake by squalene aerosol particles were also found to be slower than with the unsaturated fatty acids. ${ }^{32,33}$ One of the possible reasons for this different ${ }^{\circ} \mathrm{OH}$ uptake was attributed to the different molecular orientation of squalene and fatty acids on surfaces. It is well accepted that the fatty acids form dimers through hydrogen bonding between the acidic hydrogen and carbonyl oxygen, leading to a semicrystalline order in the liquid fatty acids. ${ }^{34-36}$ This molecular ordering is proposed to increase the density of $\mathrm{C}=\mathrm{C}$ bond at the surface, thereby increasing the reaction rate of fatty acids with gas-phase oxidants. ${ }^{37}$ In contrast, due to the lack of hydrogen bonding, the isotropic orientation of the squalene molecules on the surface does not increase the $\mathrm{C}=\mathrm{C}$ bond density resulting in a lower ${ }^{\circ} \mathrm{OH}$ uptake. ${ }^{33}$ 
Figure 3a shows the kinetics for the reaction of squalene with $50 \mathrm{ppb}$ ozone which lead to $\mathrm{k}_{1}=(1.3 \pm 0.1) \times$ $10^{-3} \mathrm{~s}^{-1}$ and $(1.2 \pm 0.1) \times 10^{-3} \mathrm{~s}^{-1}$ for dry $(\mathrm{RH}<5 \%)$ and humid $(\mathrm{RH}=50 \%)$ conditions, respectively, indicating that the $\mathrm{RH}$ does not affect the $\mathrm{O}_{3}$ kinetics. This is in accord with other studies that found the kinetics between ozone and squalene are insensitive to $\mathrm{RH}^{25,27}$ The independence of squalene/ $/ \mathrm{O}_{3}$ kinetics on $\mathrm{RH}$ is consistent with a weak interaction of water for the reactive portions of the squalene surfaces. The literature reports of the effects of $\mathrm{RH}$ on fatty acids $/ \mathrm{O}_{3}$ kinetics disagree. Previous work suggests that the kinetics of the ozone loss on linoleic acid were not affected by $\mathrm{RH},{ }^{38-40}$ whereas a later study of Zeng et al. ${ }^{41}$ found that the ozone loss increased with $\mathrm{RH}$.

Squalene Oxidation in Indoor Air. The kinetic plot for squalene oxidation in room air is shown in Figure $3 \mathrm{~b}$, where the room conditions were $\mathrm{RH}=8.6-9.9 \%, \mathrm{~T}=23.4-24.3{ }^{\circ} \mathrm{C}$ and $\mathrm{MRO}=21.6-31.8 \mathrm{ppb}$ (average $\left.\mathrm{MR}_{03}=26.7 \mathrm{ppb}\right)$. The oxidation was done with daylight entering the office $\left(\sim 1.0 \mathrm{Watt} / \mathrm{m}^{2}\right.$ from 325 to 850 $\mathrm{nm})$. The pseudo first-order rate coefficient was derived from the kinetic plot to be $(6.7 \pm 0.7) \times 10^{-4} \mathrm{~s}^{-1}$, which is very similar to that for $25 \mathrm{ppb} \mathrm{O}_{3}$ oxidation in the flow tube $\left((6.0 \pm 0.4) \times 10^{-4} \mathrm{~s}^{-1}\right)$. As can be seen in Figure $3 b$ the data for indoor air oxidation of squalene is somewhat more scattered compared to ozone oxidation in the flow tube. This could be due to the variation of the ozone mixing ratios in indoor air.

Previous studies have reported that the ${ }^{\circ} \mathrm{OH}$ radical concentrations in indoor air are as high as $\sim 10^{6}$ molecules $/ \mathrm{cm}^{3},{ }^{42-46}$ suggesting that the ${ }^{\circ} \mathrm{OH}$ radical could be an important oxidant in indoor environment. However, the similar kinetics for squalene oxidation with ozone in controlled lab conditons and with indoor air that contains a similar level of ozone (Figure 3b) suggests that ozone is the dominant oxidant in indoor air, at least in these settings.

Condensed-phase Products from Squalene/ $\mathbf{O}_{3}$ Reaction. Figure 4 presents the mass spectra of the condensed-phase products from ozone reaction with squalene obtained with positive mode DART-MS by subtracting the unreacted squalene mass spectrum from the product spectra. It is common to observe both protonated and ammoniated molecules from carbonyl-containing species $(\mathrm{C}=\mathrm{O})$ with positive DART-MS analysis. The intermediate products formed at earlier stages of the oxidation (e.g. 5 minutes) under dry condition $(\mathrm{RH}<5 \%)$ in Figure $4 \mathrm{a}$ are therefore, tentatively identified as carbonyls. For example, the products at $\mathrm{m} / \mathrm{z} 291.2,317.3$ and 385.3 are attributed to protonated C19, C22 and C27 aldehydes (Table $\mathrm{S} 1$ ), respectively, whereas those at $\mathrm{m} / \mathrm{z} 308.2,334.3$ and 402.3 are likely to be the associated ammoniated species. The intensities of these intermediate products decrease upon further oxidation with formation of products of lower masses (30 and 60 minutes in Figure 4a).

The evolution of selected products under dry conditions is illustrated by plotting absolute intensities of the products as a function of reaction time in Figure S5a. As discussed above, the C22 (m/z 317.3) and $\mathrm{C} 27(\mathrm{~m} / \mathrm{z} 385.3)$ aldehydes in Figure S5a increase during the early oxidation of squalene and then decay as the oxidation proceeds. This is in accord with the fact that the intermediate products contain $\mathrm{C}=\mathrm{C}$ bonds and are subject to sequential reaction with ozone. The end products with $\mathrm{m} / \mathrm{z} 101.0$ and $\mathrm{m} / \mathrm{z} 117.0$, on the other hand, exhibit an increase and then a levelling off. The slight decrease in the intensities of $\mathrm{m} / \mathrm{z} 101.0$ and $\mathrm{m} / \mathrm{z} 117.0$ after 30 minutes of oxidation could be due to their semi-volatile nature. The products at $\mathrm{m} / \mathrm{z}$ 
101.0 and 117.0 are tentatively identified as 4-oxopentanal $\left(\mathrm{C}_{5} \mathrm{H}_{9} \mathrm{O}_{2}{ }^{+}\right)$and levulinic acid $\left(\mathrm{LLA}, \mathrm{C}_{5} \mathrm{H}_{9} \mathrm{O}_{3}{ }^{+}\right)$, respectively. The end products between $\mathrm{m} / \mathrm{z} 200$ and 350 (60 minute oxidation in Figure 4a) are not identified and will be discussed later.

Intermediate products under dry conditions are also observed with negative mode DART-MS (Figure 5a). As suggested in Table S2, these products are attributed to carboxylic acids. This is because test experiments show that with negative DART-MS analysis of a $\mathrm{C} 10$ aldehyde, citral $\left(\mathrm{C}_{10} \mathrm{H}_{16} \mathrm{O}\right)$, and a $\mathrm{C} 10$ acid, geranic acid $\left(\mathrm{C}_{10} \mathrm{H}_{16} \mathrm{O}_{2}\right)$, the $\mathrm{C} 10$ acid is more sensitive than the $\mathrm{C} 10$ aldehyde by more than a factor of $\sim 100$ (data not shown).

Similar to the intermediate products observed with positive DART-MS, the C14 aldehydic acid ( $\mathrm{m} / \mathrm{z} 237.1)$ and $\mathrm{C} 27$ acid ( $\mathrm{m} / \mathrm{z}$ 399.3) (Figure S5b) peak at early oxidation stages and then decay with further oxidation. The two final products with $\mathrm{m} / \mathrm{z} 115.0$ and 117.0, tentatively indentified as LLA and succinic acid $\left(\mathrm{C}_{4} \mathrm{H}_{5} \mathrm{O}_{4}^{-}\right.$, SCA), whose reference mass spectra are given in Figure S6, respectively in our previous work, ${ }^{24}$ exhibit increase in the beginning and then leveling off at the end of the oxidation. The chemical identities of the possible condensed-phase products are given in Tables S1 and S2 but structural isomers are also possible. For example, 5-hydroxy-4-oxopentanal (5-HOP, MW=116.0) has been suggested to form in the squalene $/ \mathrm{O}_{3}$ reaction ${ }^{15}$ and may contribute to the signal at $\mathrm{m} / \mathrm{z} 115.0$ in the DART-MS measurement.

Figures $4 \mathrm{~b}$ and $5 \mathrm{~b}$ indicate that intermediate products formed under humid conditions $(\mathrm{RH}=50 \%)$ are similar to those under dry conditions but the end products are different. From Figure 4 it can be seen that at 60 minute oxidation more products are formed between $\mathrm{m} / \mathrm{z} 300-350$ at low RH. In addition, Figure 5 shows that the SCA $(\mathrm{m} / \mathrm{z} 117.0)$ is only observed under dry conditions. The product at $\mathrm{m} / \mathrm{z} 101.0$ in Figure 5 is tentatively identified as 4 -oxobutanoic acid $\left(\mathrm{C}_{4} \mathrm{H}_{5} \mathrm{O}_{3}^{-}\right)$.

The reaction between a $\mathrm{C}=\mathrm{C}$ bond and ozone is usually explained by a Criegee-forming mechanism. ${ }^{47}$ The addition of ozone to the $\mathrm{C}=\mathrm{C}$ bond produces primary ozonides that decompose to carbonyls (aldehydes and/or ketones) and Criegee intermediates (CI) (R1 of Scheme 1). The formation of the acids in this work is believed to be the result of the isomerization of CIs (R2 of Scheme 1).

Product Quantification. The final products from the squalene/ $\mathrm{O}_{3}$ reaction were quantified after $40 \mathrm{ng}$ squalene were oxidized with $50 \mathrm{ppb} \mathrm{O}_{3}$ for 60 minutes. The molar yields of LLA and SCA were measured to be $(230 \pm 43) \%$ and $(110 \pm 31) \%$, respectively under dry condition. As can be seen from Figure 1 the maximum yields of LLA (C-3, -7, -18 and -22 forming acids while C-6, -10, -15 and -19 forming ketones) and SCA (C-11 and -14 forming acids) from squalene oxidation can be $400 \%$ and $100 \%$, respectively. The measured SCA yield of $\sim 100 \%$ suggests that the ozone addition to C-10 and -11 and C-14 and -15 exclusively leads to acid functional groups on $\mathrm{C}-11$ and $\mathrm{C}-14$ (Figure 1). Whether or not ozone addition to other $\mathrm{C}=\mathrm{C}$ bonds in squalene all give rise to acids on $\mathrm{C}-3, \mathrm{C}-7, \mathrm{C}-18$ and $\mathrm{C}-22$ is not known. However, we note that the measured LLA yield is almost half of its maximum yield from squalene oxidation. LLA is a semi-volatile product and has been observed in the gas-phase from ozonolysis of squalene. ${ }^{15}$ In addition, as will be discussed in the next section, LLA is proposed to be involved in high molecular weight 
product formation. Thus, its yield reported in this work could be a lower limit to the overall yield. Moreover, as mentioned above, the contribution of its isomers, e.g. 5-HOP, to the LLA signal cannot be ruled out.

Under high $\mathrm{RH}(\mathrm{RH}=50 \%)$ conditions the LLA and SCA yields are reduced to $(91 \pm 15) \%$ and less than $5 \%$, respectively. Instead, 4-oxobutanoic acid ( $\mathrm{m} / \mathrm{z} 101.0)$ is observed as another main product (Figure $5 \mathrm{~b}$ ) (not quantified). The variable product distribution under different $\mathrm{RH}$ could be attributed to the reaction of water with CIs at high RH, thus decreasing the formation rates of acids. As illustrated in R3 of Scheme 1 , water can react with CIs to generate $\alpha$-hydroxyhydroperoxides ( $\alpha$-HHP), which are proposed to equilibrate with aldehydes and $\mathrm{H}_{2} \mathrm{O}_{2}{ }^{48}$ With hot helium in the DART-MS source, the $\alpha$-HHP may thermally decompose to high volatility aldehydes and $\mathrm{H}_{2} \mathrm{O}_{2}$.

High Molecular Weight (HMW) Product Formation. Figure 6 provides mass spectra of HMW products from ozonolysis of squalene obtained under positive mode DART-MS. The HMW products have been proposed to be the result of reaction of CIs with other products. ${ }^{26}$ As illustrated in Scheme 1, reaction with carbonyls leads to secondary ozonides (R4 of Scheme 1), ${ }^{49-51}$ with protic organics such as carboxylic acids producing hydroperoxides (R5 of Scheme 1$)^{37,49,52,53}$ or with other CIs to generate oligomers or polymers (not shown). ${ }^{40,52}$ We believe that more HMW products are observed with higher helium temperature in Figure 6 a because of more thermal desorption from the capillary. The production of more HMW products with higher masses of squalene on the capillaries (see Figure 6b) could be due to more cross reactions of CIs that generate oligomers or polymers.

A mass difference of 116.0 is observed between many HMW products in Figure 6b (see also Table S3), as well as in Figure $4 \mathrm{a}$ between $\mathrm{m} / \mathrm{z}$ 200-350, corresponding to the mass of $\mathrm{C}_{5} \mathrm{H}_{8} \mathrm{O}_{3}$ (LLA and/or 5-OH-4OPA). This observation is consistent with recent work on HMW products from reaction of squalene with 50 ppm $\mathrm{O}_{3}$ that indicated the involvement of $\mathrm{C}_{5} \mathrm{H}_{8} \mathrm{O}_{3}$ in $\mathrm{HMW}$ generation. ${ }^{26}$ For example, via reaction $\mathrm{R} 5$ it is possible that CIs are reacting with acids, leading to larger molecules. It has to be noted that the HMW products are only observed under dry conditions in this work, suggesting that the reaction of CIs with water dominates when $\mathrm{RH}$ is high. This would give rise to higher volatility aldehydes and $\mathrm{H}_{2} \mathrm{O}_{2}$, as discussed above.

Environmental Implications. Motivated by the fact that squalene is continually produced from skin and has been detected in indoor dust, ${ }^{54}$ it is important to better understand the nature of its multiphase oxidation processes both kinetically and mechanistically. In particular, ozone is known to be lost more rapidly in rooms with human occupancy than in rooms without. ${ }^{15}$ Within skin oil, squalene represents the largest source of double bonds and so the implication is that the enhanced loss of ozone in such spaces is largely driven by reaction with squalene. This work provides quantitative evidence of the rapid oxidation of squalene under conditions similar to those indoors, in accord with previous studies. ${ }^{20,25,27}$

With the information gained in this work it is now possible to estimate the oxidation kinetics that squalene will exhibit when deposited onto surfaces in an indoor environment as part of skin oil. In particular, in our 
past studies of skin oil oxidation we demonstrated that the squalene within skin oil is oxidized roughly one half to one third more slowly than when the squalene is present as a pure substance, for the same ozone exposure. ${ }^{24}$ Although these loss rates will be dependent on the thickness of the skin oil and squalene films (see Equation 1), we believe the thicknesses of these films were similar in that work because the squalene DART-MS signals were roughly $15 \%$ as large in the skin oil as in the pure squalene films in the kinetic studies, and squalene is predicted to represent about $10 \%$ of the skin oil composition. ${ }^{2}$ This slightly lower reactivity of ozone within the film could be due to reaction with other reactive molecules. Knowing this, we can estimate a reactive uptake coefficient for ozone via reaction with squalene in skin oil. This value will be proportionally lower than the value for pure squalene due to not only the factor of two to three lower reactivity observed, but also because squalene represents only $10 \%$ of the lipid material in skin oil. Thus, we propose that an effective room temperature uptake coefficient for ozone reaction with squalene in skin oil is on the order of 1 to $2 \times 10^{-5}$, i.e. 20 to 30 times lower than our value measured on pure squalene. Note that this quantity is not the same as the total reactive uptake coefficient for ozone on skin oil, which will have a larger value due to reactions with other unsaturated compounds in the oil.

An additional aspect of this research is that we have shown that ozone represents the most likely oxidant for squalene within indoor environments. In particular, for the first time we have measured the decay rate of squalene under genuine indoor conditions, confirming that it is similar within experimental uncertainties as that measured in a lab experiment conducted with similar ozone mixing ratios, indicating that $\mathrm{O}_{3}$ is the primary oxidant in this indoor environment. Other oxidants that have the potential to oxidize squalene are the hydroxyl radical and the nitrate radical, but their mixing ratios are many orders of magnitude lower than typical values of indoor ozone, ${ }^{1,43-45,55}$ making it unlikely that they can compete with ozone-driven oxidation unless a very large degree of radical recycling occurs within the skin oil material.

Given that ozone can oxidatively process the squalene that exists within skin oil, it is of importance to know the products from this reaction. Volatile products have already been studied, ${ }^{15}$ however this study is one of the first to investigate condensed-phase products in detail, ${ }^{26}$ including their progression through different stages of oxidation. The DART-MS technique shows that both highly oxygenated products composed of carbonyls, carboxylic acids as well as high molecular weight products are expected to form in dry indoor environments. Indeed, although the nature of the higher molecular weight products has not been established in detail, ${ }^{26}$ it is apparent that some of the lower molecular weight products are incorporated into the structures of the higher molecular weight species. It needs to now be confirmed that such species are observed on genuine indoor surfaces that have experienced human occupancy. As well, given that some of the same late-stage oxidation products, such as the small acids, could be formed in the gas phase via ozone reacting with early-stage volatile oxidation products, there is the potential that they could also be incorporated into secondary organic aerosol material arising from squalene oxidation. ${ }^{23}$

The effects that these products have upon loss of indoor gas-phase oxidants, via heterogeneous reactions, need to be evaluated. As well, they should be tested for their potential toxicity, given that oxidation increases the redox cycling abilities of the surfaces. ${ }^{25}$ Particularly important are the highly oxygenated 
products including the hydroperoxides that could form via R3 and/or R5 of Scheme 1, as well as the high molecular weight products. Importantly, these results demonstrate that the product distribution will change as the relative humidity in indoor environments is changed, arising through different pathways from the Criegee intermediate.

\section{ACKNOWLEDGEMENTS}

The authors would like to acknowledge funding from the Alfred P. Sloan Foundation (Grant G2016-7049).

The authors declare no competing financial interest.

Supporting Information Available. 6 figures and 3 talbes showing gas-phase products from squalene oxidation (Figure S1), squalene oxidation in room air (Figure S2), mass spectrum of squalene obtained with positive mode DART-MS (Figure S3), DART-MS calibration of squalene, succinic acid and levulinic acid (Figure S4), evolution of condensed-phase products from squalene/O 3 reaction (Figure S5), DARTMS mass spectra of succinic acid and levulinic acid (Figure S6), possible products from squalene/O 3 reaction (Table S1 and S2) and $\mathrm{m} / \mathrm{z}$ for mass difference $(\Delta \mathrm{m} / \mathrm{z}$ ) of 116.0 between the high molecular weight products (Table S3). This material is available free of charge via the Internet at http://pubs.acs.org.

\section{REFERENCES}

1. Weschler, C. J. Roles of the human occupant in indoor chemistry. Indoor Air 2016, 26, 6-24.

2. Nicolaides, N. Skin lipids - their biochemical uniqueness. Science 1974, 186, 19-26.

3. Laden, K.; Sptizer, R. Identification of a natural moisturizing agent in skin. J. Soc. Cosmet. Chem. 1967, 18, 351-360.

4. Pochi, P. E.; Downing, D. T.; Strauss, J. S. Sebaceous gland response in man to prolonged total caloric deprivation. J. Invest. Dermatol. 1970, 55, 303-318.

5. Marstein, S.; Jellum, E.; Eldjarn, L. The concentration of pyroglutamic acid (2-pyrrolidone-5carboxylic acid) in normal and psoriatic epidermis, determined on a microgram scale by gaschromatography. Clin. Chim. Acta 1973, 49, 389-395.

6. Downing, D. T.; Strauss, J. S. Synthesis and composition of surface lipids of human skin. J. Invest. Dermat. 1974, 62, 228-244.

7. Rawlings, A. V.; Scott, I. R.; Harding, C. R.; Bowser, P. A. Stratum-corneum moisturization at the molecular-level. J. Invest. Dermat. 1994, 103, 731-740.

8. Coleman, B. K.; Destaillats, H.; Hodgson, A. T.; Nazaroff, W. W. Ozone consumption and volatile byproduct formation from surface reactions with aircraft cabin materials and clothing fabrics. Atmos. Environ. 2008, 42, 642-654.

9. Fischer, A.; Ljungstrom, E.; Langer, S. Ozone removal by occupants in a classroom. Atmos. Environ. 2013, 81, 11-17.

10. Tamas, G.; Weschler, C. J.; Bako-Biro, Z.; Wyon, D. P.; Strom-Tejsen, P. Factors affecting ozone removal rates in a simulated aircraft cabin environment. Atmos. Environ. 2006, 40, 6122-6133.

11. Rim, D.; Novoselec, A.; Morrison, G. The influence of chemical interactions at the human surface on 
breathing zone levels of reactants and products. Indoor Air 2009, 19, 324-334.

12. Rai, A. C.; Guo, B.; Lin, C. H.; Zhang, J. S.; Pei, J. J.; Chen, Q. Y. Ozone reaction with clothing and its initiated particle generation in an environmental chamber. Atmos. Environ. 2013, 77, 885-892.

13. Fadeyi, M. O.; Weschler, C. J.; Tham, K. W.; Wu, W. Y.; Sultan, Z. M. Impact of human presence on secondary organic aerosols derived from ozone-initiated chemistry in a simulated office environment. Environ. Sci. Technol. 2013, 47, 3933-3941.

14. Weschler, C. J.; Wisthaler, A.; Cowlin, S.; Tamas, G.; Strom-Tejsen, P.; Hodgson, A. T.; Destaillats, H.; Herrington, J.; Zhang, J. J.; Nazaroff, W. W. Ozone-initiated chemistry in an occupied simulated aircraft cabin. Environ. Sci. Technol. 2007, 41, 6177-6184.

15. Wisthaler, A.; Weschler, C. J. Reactions of ozone with human skin lipids: sources of carbonyls, dicarbonyls, and hydroxycarbonyls in indoor air. Proc. Natl. Acad. Sci. U.S.A. 2010, 107, 6568-6575.

16. Wisthaler, A.; Tamas, G.; Strom-Tejsen, P.; Space, D.; Beauchamp, J.; Hansel, A.; Mark, T.D.; Weschler, C.J. Products of ozone-initiated chemistry in a simulated aircraft environment. Environ. Sci. Technol. 2005, 39, 4823-4832.

17. Rai, A.C.; Guo, B.; Lin, C.H.; Zhang, J.; Pei, J.; Chen, Q. Ozone reaction with clothing and its initiated VOC emissions in an environmental chamber. Indoor Air 2014, 24, 49-58.

18. Pandrangi, L.S.; Morrison, G.C. Ozone interaction with human hair: ozone uptake rates and products formation. Atmos. Environ. 2008, 42, 5079-5089.

19. Fruekilde, P.; Hjorth, J.; Jensen, N. R.; Kotzias, D.; Larsen, B. Ozonolysis at vegetation surfaces: a source of acetone, 4-oxopentanal, 6-methyl-5-hepten-2-one, and geranyl acetone in the troposphere. Atmos. Environ. 1998, 32, 1893-1902.

20. Wells, J. R.; Morrison, G. C.; Coleman, B. K. Kinetics and reaction products of ozone and surfacebound squalene. J. ASTM Int. 2008, 5, 1-12.

21. Matsunaga, S.; Mochida, M.; Kawamura, K. Variation on the atmospheric concentrations of biogenic carbonyl compounds and their removal processes in the northern forest at Moshiri, Hokkaido Island in Japan. J. Geophys. Res. 2004, 109, D04302 DOI: 10.1029/2003JD004100.

22. Matsunaga, S.; Mochida, M.; Kawamura, K. High abundance of gaseous and particulate 4-oxopentanal in the forestal atmosphere. Chemosphere 2004, 55, 1143-1147.

23. Wang, C.Y.; Waring, M.S. Secondary organic aerosol formation initiated from reactions between ozone and surface-sorbed squalene. Atmos. Environ. 2014, 84, 222-229.

24. Zhou, S.; Forbes, M.W.; Katrib, Y.; Abbatt, J.P.D. Rapid oxidation of skin oil by ozone. Environ. Sci. Technol. Letters 2016, 3, 170-174.

25. Fu, D.; Leng, C. B.; Kelley, J.; Zeng, G.; Zhang, Y. H.; Liu, Y. ATR-IR study of ozone initiated heterogeneous oxidation of squalene in an indoor environment. Environ. Sci. Technol. 2013, 47, 10611-10618.

26. Fooshee, D. R.; Aiona, P. K.; Laskin, A.; Laskin, J.; Nizkorodov, S. A.; Baldi, P. F. Atmospheric oxidation of squalene: molecular study using COBRA modeling and high-resolution mass spectrometry. Environ. Sci. Technol. 2015, 49, 13304-13313.

27. Petrick, L.; Dubowski, Y. Heterogeneous oxidation of squalene film by ozone under various indoor conditions. Indoor Air 2009, 19, 381-391.

28. Cody, R.B.; Laramee, J.A.; Durst, H.D. Versatile new ion source for the analysis of materials in open 
air under ambient conditioins. Anal. Chem. 2005, 77, 2297-2302.

29. Zhou, S.; Forbes, M.W.; Abbatt, J.P.D. Application of direct analysis in real time-mass spectrometry (DAR-MS) to the study of gas-surface heterogeneous reactions: focus on ozone and PAHs. Anal. Chem. 2015, 87, 4733-4740.

30. Cornelio-Clark, P.A.; Gardella Jr., J.A. Surface chemistry effects and sampling depth of molecular ions from static secondary ion mass spectrometer of Langmuir-Boldgett fatty acid films. Langmuir1 991, 7, 22279-2286.

31. Zahardis, J.; Petrucci, G.A. The oleic acid-ozone heterogeneous reaction system: products, kinetics, secondary chemistry, and atmospheric implications of a model system - a review. Atmos. Chem. Phys. 2007, 7, 1237-1274.

32. Nah, T.; Kessler, S. H.; Daumit, K. E.; Kroll, J. H.; Leone, S. R.; Wilson, K. R. OH-initiated oxidation of sub-micron unsaturated fatty acid particles. Phys. Chem. Chem. Phys. 2013, 15, 18649-18663.

33. Nah, T.; Kessler, S.H.; Daumit, K.E.; Kroll, J.H.; Leone, S.R.; Wilson, K.R. Influence of molecular structure and chemical functionality on the heterogeneous $\mathrm{OH}$-initiated oxidation of unsaturated organic particles. J. Phys. Chem. A 2014, 118, 4106-4119.

34. Sliwiok, J.; Rzepa, J.; Kowalska, T. Mechanism of the hydroperoxide destruction in the oxidized methyl oleate, oleyl alcohol and oleic acid. Microchem. J. 1976, 21, 250-260.

35. Iwahashi, M.; Kasahara, Y.; Matsuzawa, H.; Yagi, K.; Nomura, K.; Terauchi, H.; Ozaki, Y.; Suzuki, M. Self-diffusion, dynamical molecular conformation, and liquid structures of N-saturated and unsaturated fatty acids. J. Phys. Chem. B 2000, 104, 6186-6194.

36. Iwahashi, M.; Kasahara, Y. Dynamic molecular movements and aggregation structures of lipids in a liquid state. Curr. Opin. Colloid Interface Sci. 2011, 16, 359-366.

37. Hearn, J. D.; Lovett, A. J.; Smith, G. D. Ozonolysis of oleic acid particles: evidence for a surface reaction and secondary reactions involving Criegee intermediates. Phys. Chem. Chem. Phys. 2005, 7, 501-511.

38. Moise, T.; Rudich, Y. Reactive uptake of ozone by aerosol associated unsaturated fatty acids: kinetics, mechanism, and products. J. Phys. Chem. A 2002, 106, 6469-6476;

39. Thornberry, T.; Abbatt, J. P. D. Heterogeneous reaction of ozone with liquid unsaturated fatty acids: detailed kinetics and gas-phase product studies. Phys. Chem. Chem. Phys. 2004, 6, 84-93.

40. Hearn, J. D.; Smith, G. D. Kinetics and product studies for ozonolysis reactions of organic particles using aerosol CIMS. J. Phys. Chem. A 2004, 108, 10019-10029.

41. Zeng, G.; Holladay, S.; Langlois, D.; Zhang, Y. H.; Liu, Y. Kinetics of heterogeneous reaction of ozone with linoleic acid and its dependence on temperature, physical state, $\mathrm{RH}$, and ozone concentration. J. Phys. Chem. A 2013, 117, 1963-1974.

42. Weschler, C.J.; Shields, H.C. Production of the hydroxyl radical in indoor air. Environ. Sci. Technol. 1996, 30, 3250-3258.

43. Singer, B.C.; Coleman, B.K.; Destaillats, H.; Hodgson, A.T.; Lunden, M.M.; Weschler, C.J.; Nazaroff, W.W. Indoor secondary pollutants from cleaning product and air freshner use in the presence of ozone. Atmos. Environ. 2006, 40, 6696-6710.

44. Weschler, C. J.; Shields, H.C. Measurements of the hydroxyl radical in a manipulated but realistic indoor environment. Environ. Sci. Technol. 1997, 31, 3719-3722. 
45. White, I.R.; Martin, D.; Munoz, M.P.; Petersson, F.K.; Henshaw, S.J.; Nickless, G.; Lloyd-Jones, G.C.; Clemitshaw, K.C.; Shallcross, D.E. Use of reactive tracers to determine ambient $\mathrm{OH}$ radical concentrations: application within the indoor environment. Environ. Sci. Technol. 2010, 44, 6269-6274. 46. Alvarez, E.G.; Amedro, D.; Afit, C.; Gligorovski, S.; Schoemaecker, C.; Fittschen, C.; Doussin, J-F.; Wortham, H. Unexpected high indoor hydroxyl radical concentrations associated with nitrous acid. Proc. Natl. Acad. Sci. U.S.A. 2013, 110, 13294-3299.

47. Criegee, R. Mechanisms of ozonolysis. Angew Chem. Int. Ed Engl. 1975, 14, 745-752.

48. Zhao, R.; Lee, A.K.Y.; Soong, R.; Simpson, A.J.; Abbatt, J.P.D. Formation of aqueous-phase $\alpha-$ hydroxyhydroperoxides ( $\alpha$-HHP): potential atmospheric impacts. Atmos. Chem. Phys. 2013, 13, 58575872.

49. Ziemann, P. Aerosol products, mechanisms, and kinetics of heterogeneous reactions of ozone with oleic acid in pure and mixed particles. Faraday Discuss. 2005, 130, 469-490.

50. Zahardis, J.; Petrucci, G.A. The oleic acid-ozone heterogeneous reaction system: products, kinetics, secondary chemistry, and atmospheric implications of a model system - a review. Atmos. Chem. Phys. 2007, 7, 1237-1274.

51. Hung, H-M.; Katrib, Y.; Martin, S.T. Products and mechanisms of the reaction of oleic acid with ozone and nitrate radical. J. Phys. Chem. A 2005, 109, 4519-4530.

52. Zahardis, J.; LaFranchi, B.W.; Petrucci, G.A. Direct observation of polymerization in the oleic acidozone heterogeneous reaction by photoelectron resonance capture ionizatoin aerosol mass spectrometry. Atmos. Environ. 2006, 1661-1670.

53. Katrib, Y.; Martin, S.T.; Hung, H-M.; Rudich, Y.; Zhang, H.; Slowik, J.G.; Davidovits, P.; Jayne, J.T.; Worsnop, D.R. Products and mechanisms of ozone reaction with oleic acid for aerosol particles having core-shell morphology. J. Phys. Chem. A 2004, 108, 6685-6695.

54. Weschler, C. J.; Langer, S.; Fischer, A.; Bekö, G.; Toftum, J.; Clausen, G. Squalene and cholesterol in dust from Danish homes and daycare centers. Environ. Sci. Technol. 2011, 45, 3872-3879.

55. Carslaw, N. A new detailed chemical model for indoor air pollution. Atmos. Environ. 2007, 41, 11641179. 